\title{
Blood Group AB
}

National Cancer Institute

\section{Source}

National Cancer Institute. Blood Group AB. NCI Thesaurus. Code C76248.

A blood group indicating the presence on erythrocytes of both the A and $B$ forms of the

$\mathrm{H}$ Antigen. 